\title{
Abstract \\ Social capital; A link towards health and wellbeing among minority pregnant women?
}

Agampodi TC ${ }^{1}$, Husna $\mathrm{F}^{1^{*}}$, Agampodi $\mathrm{SB}^{1}$, Glozier $\mathrm{N}^{2}$, Siribaddana $\mathrm{SH}^{3}$

${ }^{1}$ Department of Community Medicine, Faculty of Medicine and Allied Sciences, Rajarata University of Sri Lanka

${ }^{2}$ Brain and Mind Research Institute \& Discipline of Psychiatry, Sydney Medical School, University of Sydney

${ }^{3}$ Department of Medicine, Faculty of Medicine and Allied Sciences, Rajarata University of Sri Lanka

\begin{abstract}
\section{Background}

Social capital is defined as "features of social organization, such as networks, norms and social trust that facilitate coordination for mutual benefit". In Sri Lanka the concept of social capital has not been assessed in relation to health. This preliminary study was to explore social capital among Muslim pregnant women in Medical Officer of Health $(\mathrm{MOH})$ area Nuwaragam Palatha Central (NPC) with the view of generating hypotheses on its effect on health.
\end{abstract}

\section{Methods}

We conducted a qualitative study using solicited diaries followed by in-depth interviews. Nine participants were selected purposively with the help of Public Health Midwives. Participants were asked to document their social relationships in a diary provided for two weeks. After completion of the diaries, we conducted in-depth interviews to further explore social capital. Data saturation was achieved. Data analysis was done using framework approach. Ethical clearance was obtained by the Research and Ethics Committee, Faculty of Medicine and Allied Sciences, Rajarata University of Sri Lanka.

\section{Results}

Eight pregnant women completed the diaries and the in-depth interviews. Bonding, with reference to husband, people at home and neighborhood was very high in this community. Social isolation was not observed. Mothers did not mention about stressors. Neighborhood reciprocity, sense of belonging, supports on household chores and perceived love and care were prominent cognitive dimensions observed. Social networks with relatives, neighbors and friends, were dense. These rich networks seem to buffer their physical discomforts. Their expressions over these relationships followed positive emotions, which may lead to mental wellbeing. Although they belong to a minority ethnic group the bridging and linking ties were also commendable.

\section{Conclusions}

Pregnant women in Muslim communities of MOH area of NPC possess very high levels of social capital, which could lead to favorable health outcomes in pregnancy. We encourage quantitative studies on social capital and health to test these hypotheses.

Key words: Social capital; Pregnant women; Health and wellbeing

Copyright: $(2015$ Agampodi TC et al. This is an open access article distributed under the Creative Commons Attribution License, which permits unrestricted use, distribution, and reproduction in any medium, provided the original work is properly cited.

\footnotetext{
* Correspondence : f.husnawahid@gmail.com
}

Cite this abstract as: Agampodi TC, Husna F, Agampodi SB, Glozier N, Siribaddana SH. Social capital; A link towards health and wellbeing among minority pregnant women?. Anuradhapura Medical Journal 2015;9 (2Supp):S01. DOI: http://dx.doi.org/10.4038/amj.v9i2Supp.7550 
